«En 28 de diciembre del dicho año, salieron Mayorga y Copín, imaginario, a ajustar en Ladrada el aliso necesario para la talla e imaginería del retablo» ${ }^{25}$.

La coincidencia del apellido y la cercanía de las fechas sugieren la posibilidad de que se tratara de la misma persona que trabajó en el retablo de Oviedo; pero lo limitado de la noticia recomienda la prudencia. No obstante, la nutrida presencia de artistas burgaleses en Toledo a principios del siglo XVI vendría a justificar la residencia de Mayorga, un artífice castellano-leonés, en Toledo, cuya catedral, por aquellos años, emprendía ambiciosas empresas decorativas en clave renacentista. Pedro Berruguete, Felipe Vigarny, Juan de Borgoña son figuras cuya actividad se localiza primero en Castilla la Vieja para, de inmediato, documentarse en Toledo con el cambio de siglo. Quizás la relación de Mayorga con Pedro Berruguete, ya apuntada, pudiera tener algo que ver con la presencia de aquél en Toledo en 1499.

JAVIER GONZÁLEZ SANTOS Universidad de Oviedo

\title{
«NUEVOS DIBUJOS DE LA PLAZA MAYOR DE MADRID»
}

Como mercado y centro ceremonial principal, la Plaza Mayor era el más importante proyecto de arquitectura civil en el Madrid de los Austrias. Con la forma de su arquitectura, la plaza estableció una norma de diseño para la reforma urbana de la naciente capital española. Los dibujos arquitectónicos de la Plaza Mayor de esta época son raros y, así, la reciente aparición de dos nuevas representaciones en el Archivo de Villa de Madrid merecen atención especial ${ }^{1}$.

El primero de los dibujos es un plano interior de gran rareza. Con fecha 24 de octubre de 1618, el dibujo ilustra la primera planta residencial encima de la Carnicería, al lado meridional de la plaza (Fig. 1). El dibujo nos da una clara idea de los espacios interiores en las plantas superiores de la Plaza Mayor ${ }^{2}$. En este caso, la residencia está compuesta de cinco aposentos, dos alcobas, dos cocinas, y tres salas con balcones que dan a la plaza.

25 Pérez Sedano, Francisco, Datos documentales inéditos para la Historia de Arte Español. Notas del Archivo de la Catedral de Toledo, redactadas sistemáticamente, en el siglo XVIII, por el canónigo-obrero Don-, Madrid, Centro de Estudios Históricos, 1914, p. 22. Mayorga no figura, en cambio, en la nómina de artífices que trabajaron el retablo publicada por Sixto Ramón Parro, (Toledo en la mano, Toledo, 1857, tomo I, pp. 93-94 y 91-101 pássim). La hechura de esta importante obra abarcó los años 1499-1504, coincidiendo con la prelatura del cardenal fray Francisco Jiménez de Cisneros.

Los dibujos protagonistas de este artículo son nuevos testamentos de la riqueza de la documentación conservada en el Archivo de Villa de Madrid (AVM). El autor desea expresar su sincera gratitud a José María Bernáldez, Director, y a Rosario Sánchez y Carmen Cayetano por su ayuda generosa durante años investigando en el archivo municipal. También agradezco a Claudia Sieber quien me ha dirigido al segundo de los dibujos analizados aquí, y a Consuelo García Devesa por su ayuda en la traducción del artículo. Para una historia revisada de los edificios, usos, y significaciones de la Plaza Mayor de Madrid en su contexto local, español, e internacional, véase la tesis doctoral del autor, The Plaza Mayor of Madrid: Architecture, Urbanism, and the Imperial Capital, 1560-1640, Princeton University, 1996.

- 2 AVM: Secretaría 1-163-3. Este dibujo, encontrado en 1995, nos hace vislumbrar la enorme riqueza de documentos que se encuentra en este archivo, y la imperiosa necesidad de prestar cuidadosa atención a este tesoro. Para una discusión sobre la importancia de viviendas de múltiples pisos en Madrid, véase Bonet Correa, Antonio, «El 
Dibujos e imágenes pintadas de la Plaza Mayor suelen indicar el espacio urbano en alzado, y muchas veces adornado para fiestas. Sólo en pocas instancias, como en el plano de la disposición de la primera planta del Peso Real, vislumbramos los espacios en que ocurió la vida cotidiana en la plaza central de Madrid ${ }^{3}$. Los planos más conocidos de la Plaza Mayor nos trasmiten el perímetro de la plaza con poca atención a sus espacios interiores o a su entorno urbano. Por ejemplo, los dibujos de 1581, atribuídos al arquitecto real Juan de Valencia en el Archivo de Zabálburu en Madrid, dan noticias de manzanas masivas que no pudieron existir. En el plano de Juan Gómez de Mora, de 1626, en la Biblioteca Vaticana, las líneas de las calles se extienden al borde del papel, con poca exactitud ${ }^{4}$. En estos dos dibujos, vemos calles divorciadas de su función de ordenar el espacio urbano y, además, cualquier indicación del espacio interior está suprimida.

El nuevo dibujo de la Carnicería no solo nos sitúa el edificio dentro del contexto de la Plaza Mayor y su entorno, sino que también nos permite una visión íntima de la disposición interior de una vivienda de múltiples niveles. Como varios otros planos para la reforma de la Plaza Mayor a principios del siglo XVII, el dibujo está firmado por el arquitecto Juan Gómez de Mora, quien incluye las palabras siguientes:

Planta Alta al andar de la Plaça en la p[lan]ta prinçipal que tiene la Villa donde sobre la entrada de la Carniçeria donde se demuestra la escalera principal p[ar]a las fiestas y bibiendas en cada suelo las quales se an de mandar por escalera a parte.

Bajo la descripción del arquitecto, el escribano del Ayuntamiento Pedro Martínez, nota la decisión tomada por la Junta de la Plaza Mayor el 31 de noviembre de 1618, de ejecutar el proyecto de acuerdo con el diseño ${ }^{5}$.

El total del espacio residencial queda contenido dentro de un plano rectangular. Esta regularidad nos refleja el esfuerzo para la reorganización de la Plaza Mayor iniciado en los años 1580. Después de las reformas iniciales del siglo XVI, se ordenó la demolición de la acera de la Carnicería en la Plaza, en septiembre de 1617. De noviembre de 1618 a enero de 1620, Luis Bravo y tres asistentes —Juan de Lázaro, Juan de Urosa, y Andrés de San Románreconstruyeron las casas encima de la Carnicería siguiendo un plano de Juan Gómez de Mora, que debe ser el que se publicó aquí por primera vez ${ }^{6}$. Como resultado del alineamiento del

plano de Juan Gómez de Mora de la Plaza Mayor de Madrid en 1636». Anales del Instituto de Estudios Madrileños, IX, 1973, pp. 15-53.

3 Sobre el dibujo del Peso Real (AVM: Secretaría 1-163-20) y otros dibujos del taller de Juan Gómez de Mora, véase el catálogo importante de Tovar Martín, Viginia, Gómez de Mora, Juan (1586-1648): Arquitecto y Trazador del Rey y Maestro Mayor de Obras de la Villa de Madrid, Madrid, 1986.

4 Sobre los dibujos en el Archivo de Zabálburu y la Biblioteca Vaticana, véase Íñiguez Almech, Francisco, «Juan de Herrera y las reformas en el Madrid de Felipe II». Revista de la Biblioteca, Archivo y Museo, XIX, 1950, pp. 3-108.

${ }_{5}$ La notación de Martínez es como sigue: «En $\mathrm{M}^{\mathrm{d}}$ a [3-XI-1618] se pres ${ }^{\text {to }}$ esta planta en la junta estando en ella los $\mathrm{S}^{\text {es }}$ Po de Tapia del Cons ${ }^{\circ}$ de su $\mathrm{Mg}^{\mathrm{d}}$ y Fran $^{\text {co }}$ de Villasis su correg ${ }^{\text {dor }}$ desta $\mathrm{V}^{\mathrm{a}} \mathrm{d}_{\text {Gabriel de Alarcon Ju}}{ }^{\circ}$ de Pinedo Fran ${ }^{\mathrm{co}}$ Enrriqz de Villacorta y $\mathrm{d} \mathrm{Fr}^{\mathrm{do}}$ de Vallejo regidores y comisarios de la obra de la plaça y se acordo que se ex ${ }^{\text {te }}$ y conforme a ella se labre y lo senalaron.»

6 Los nombres de obreros de varias facetas de la reforma de la Plaza Mayor, están registrados en los contratos y cuentas manejados por Cristóbal de Medina; véase AVM: Contaduría 3-726-1. Las cuentas contienen cientos de folios sin paginación y arreglados sin orden, para los años de 1617 a 1621 . Aparentèmente, Medina estaba familiarizado con las obras reales en Madrid antes de asumir su puesto en la administración de la Plaza Mayor. Ya en el 7 de diciembre de 1617, era contador para obras en el Alcázar; véase Archivo Histórico de Protocolos de Madrid: Protocolo 3309, fols. 433r-444r. Bravo y sus ayudantes en la Carnicería reformaron completamente las residencias, desde las bóvedas del sótano hasta las chimeneas y suelos de los pisos superiores, y hasta los detalles de la fachada y tejado; véase AVM: Secretaría 1-164-6, 31 de enero de 1620. 
alzado de la Plaza Mayor y de la reconstrucción de los patios traseros de la Carnicería, se regulariza el plano del edificio.

Frente al lado meridional de la Plaza Mayor hay tres salas grandes que se abren a un balcón continuo con cinco puertaventanas. Detrás de las salas, el interior está dividido en cinco aposentos, más dos alcobas y dos cocinas, en un arreglo no bien resuelto. El arquitecto ha situado los aposentos al lado de los muros de carga para hacerlas más abrigadas. Un pasillo a la izquierda conecta las viviendas con una espaciosa escalera que da a la plaza. Gómez de Mora sugiere que fue por esta escalera que se hizo el dibujo. Otra escalera más modesta detrás de la cocina occidental, da acceso a un patio demarcado por cinco pilares, en un corredor que facilita la entrada de luz al interior.

La representación de aposentos en el plano de la Carnicería sugiere que los espacios interiores en el entorno de la Plaza Mayor eran pequeños. Exactamente cómo funcionaban estos aposentos con las cocinas y alcobas queda sin aclarar. El dibujo puede funcionar como un interior singular, quizá habitado por una familia, o como tres interiores separados, o como un grande espacio comunal destinado quizá para cinco individuos ${ }^{7}$. El hecho de que haya dos escaleras, sugiere un cierto nivel de decoro mantenido en la vivienda. Una daba entrada a las salas, la escalera principal, desde la Plaza Mayor, mientras que la escalera del patio estaba reservada para usos de servicio.

Otros documentos sugieren que la realización de la escalera principal presentó dificultades con los vecinos. Por ejemplo, el pastelero Alonso Zinos, cuya casa está situada a la izquierda de la Carnicería en el plano de 1618, no pudo ensanchar su casa en Mayo 1618 por razón de la escalera proyectada ${ }^{8}$. Como propiedad de la Villa, las viviendas encima de la Carnicería eran importantes fuentes de arrendamiento para el Ayuntamiento. Por estar situadas enfrente a la Panadería, donde la familia real asistía a las fiestas, las ventanas de la Carnicería ofrecían asientos muy deseados para el regocijo de las fiestas por parte de los regidores madrileños. Ya en 1599, durante las celebraciones para la entrada de Margarita de Austria, el residente Alberto Dávila fue pagado por el Ayuntamiento para dejar al Corregidor el uso de su balcón para asistir a una fiesta de toros ${ }^{9}$. Y, así, los residentes como Zinos, que oponían resistencia a la reforma del edificio, recibieron poca atención de los regidores.

El cronista Jerónimo de Quintana escribió de la arquitectura de la Carnicería en su famosa historia de Madrid de $1629^{10}$. Quintana notaba que el edificio fue construido

con soportales muy bien labrados, que sustentan colunas con sus basas, y capiteles de piedra gruesas alrededor de un gran patio, debajo de los quales están las tablas donde se pesa el mantenimiento. Tiene vivienda para el Alcayde de ella, y otras piezas para los repesos; entrase a ella por dos puertas, una sale a la plaza, y otra a otra calle para el desahogo de la gente, y entre ambas con sus portadas de cantería, y escudos con las armas de la Villa.

7 La evidencia de la disposición de vivienda comunal en la Plaza Mayor se ve en unos planos del siglo XIX de las plantas superiores de la Panadería, que incluyen detalles como baños comunales. Véase Pérez Arroyo, Salvador, «La Casa de la Panadería. Apuntes para una reconstrucción de su evolución tipológica». Villa de Madrid, XXIII, 1985, pp. 43-52.

8 Sobre el pleito de Zinos con el Ayuntamiento y su demanda por «ocho pies sobre los portales donde esta la romana de la Carnicería,» véase AVM: Secretaría 1-163-1, 14 de mayo de 1618 a 26 de marzo de 1619. El caso de Zinos indica aspectos de la arquitectura de la Carnicería corroborados en las cuentas para la reforma de la Plaza Mayor.

9 AVM: Secretaría 10-232-100, citado por Benito Ruano, Eloy, «Recepción madrileña de la Reina Margarita de Austria». Anales del Instituto de Estudios Madrileños, I, 1966, p. 95.

${ }_{10}$ Quintana, Jerónimo de: A la muy antigua, noble y coronada Villa de Madrid. Historia de su antigüedad, nobleza y grandeza, Madrid, 1629. 

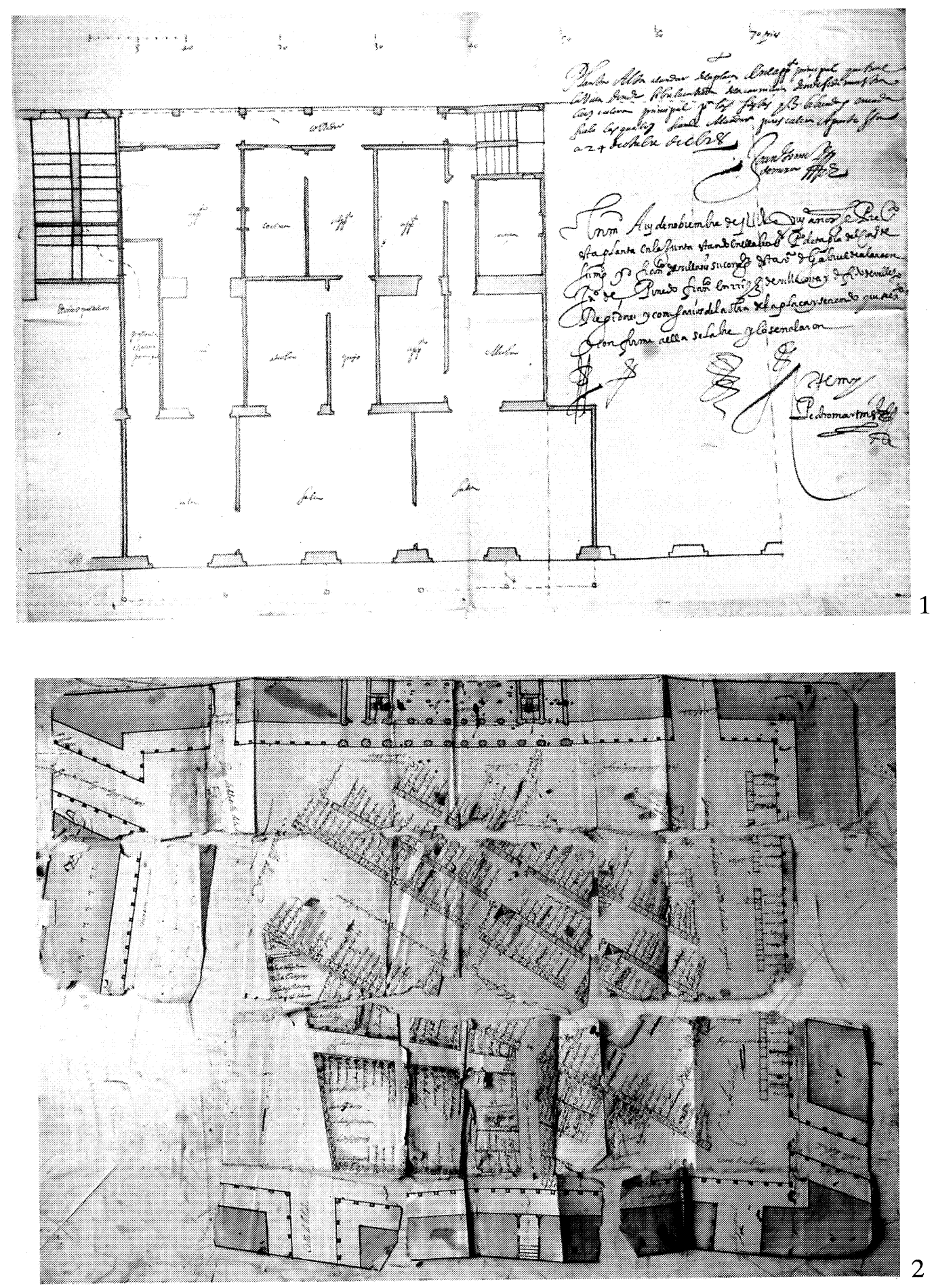

Figura 1. Taller de Juan Gómez de Mora, Traza de vivienda encima de la Carnicería, 1618, Madrid, Archivo de la Villa.

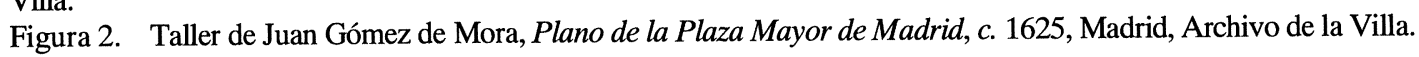


El plano de la Carnicería analizado en este artículo, corrobora la existencia de un patio con un corredor trasero y columnas. Otro dibujo inédito de la Plaza Mayor en el Archivo de Villa, indica la plaza preparada con puestos y mesas para el mercado, e incluye un detalle de la puerta de entrada a la Carnicería ${ }^{11}$ (Fig. 2). Con una fecha alrededor del 1625, este dibujo también lleva la firma de Juan Gómez de Mora, aunque está claro que la parte central de la imagen ha sido retocada por otras manos. Entrando en la Carnicería hay dos puertas que dan a espacios lindantes, cada uno con puertas que se abren a la plaza, como está indicado en el alzado de la Carnicería en Windsor Castle y en el plano que hay en en la Biblioteca Vaticana ${ }^{12}$. Inmediatamente enfrente, está una escalera que da al patio mencionado por Quintana, que parece estar situado a un nivel más bajo que la plaza por la topografía irregular del sitio.

El plano de la Plaza Mayor en el Archivo de Villa, que se publica ahora por primera vez, incluye muchos detalles además de las entradas y salidas de la Carnicería. Es un documento de suma importancia en la historia de la Plaza Mayor y del funcionamiento de un mercado en una ciudad europea en la época Moderna ${ }^{13}$. Es muy probable que el dibujo represente la visualización de una relación de los vendedores de la Plaza Mayor, llevado a cabo por el escribano del Ayuntamiento Manuel de Robles en 1625. La relación de Robles está acompañada por un apunte ${ }^{14}$ (Fig. 3). El apunte indica los nombres de los mercaderes en sus propios sitios, que están dispuestos paralelamente al eje diagonal de la Calle de Atocha y Calle Nueva de la Puerta de Guadalajara. Parece que este curioso documento fue posteriormente modificado para darle la forma visual representado en la figura 2.

Sin fecha y en mal estado de conservación, el plano de la Plaza Mayor está guardado con la relación de Robles de $1625^{15}$. Está bien pulido e incluye varias tintas. El importante dibujo que demarca el cercamiento arquitectónico de la Plaza Mayor y los espacios del mercado contenido, debió ser usado como una imagen de presentación para los alcaldes de Corte o el Ayuntamiento. Con dos excepciones notables, la disposición de la Plaza Mayor en este plano se adecúa al dibujo firmado por Juan Gómez de Mora en la Biblioteca Vaticana. Partiendo de la imagen de 1626, el plano del mercado en el Archivo de Villa exhibe correctamente el ángulo de entrada de la Calle de Toledo a la Plaza, pero omite la Calle de la Sal en la esquina noreste ${ }^{16}$.

En el centro de la Plaza Mayor, los puestos de comestibles, tablas de verduras, y mesas con turrones se organizan por la diagonal del eje Calle Nueva-Calle de Atocha, y aparecen limitados por cuatro calles marcando dos ejes norte-sur. En el triángulo a la parte norte, tres

11 AVM: Secretaría 1-167-1. El dibujo, que existe en fragmentos con necesidad de restauración, fue descubierto por Sieber, Claudia: The Invention of a Capital: Philip II and the First Reform of Madrid, tesis doctoral, The Johns Hopkins University, 1986, quien incluye una representación esquemática del dibujo. Sieber da la fecha de 1608 al dibujo por razón de documentación que acompañan al dibujo en el mismo legajo. Después de investigaciones posteriores y de la observación del estilo del dibujante, el dibujo debe fecharse alrededor de 1625 . El autor agradece la opinión experta de Rosario Sánchez y Carmen Cayetano por su ayuda para fechar el dibujo.

12 El plano en el Vaticano ha sido ya mencionado; mientras el alzado fue publicado por primera vez por Marías, Fernando y Bustamante, Agustín, «De las Descalzas Reales a la Plaza Mayor: Dibujos madrileños en Windsor Castle de la Colección de Cassiano dal Pozzo», en Cinco siglos de arte en Madrid (XV-XX), Madrid, 1991, pp. 74-85.

Sobre el papel de los mercados en ciudades europeas, véase Calabi, Donatella, Il mercato e la città: Piazze, strade, architetture d'Europa in età moderna, Venecia, 1993.

${ }^{14}$ AVM: Secretaría 1-167-1.

15 Correspondencias entre los nombres de los mercaderes en el informe de Robles y el plano sin fecha, sugiere que las dos imagenes fueran preparadas a la vez.

${ }_{16}$ La ausencia de la Calle de la Sal es difícil de explicar, dado que la reforma de la Plaza Mayor fue realizada en 1622. Como la Calle Imperial, representada sin exactitud en el plano, la Calle de la Sal se abría a la Plaza bajo soportales. 
filas de puestos corren paralelas a la diagonal central, con aproximadamente 138 puestos alineados en cuatro agrupaciones. Unas aperturas permiten el acceso a la Calle de los Bodegones, a los soportales de la Panadería, y a dos repesos, uno sirviendo a la Corte y el otro al gobierno municipal. Como era el caso en los años 1580, la parte meridional de la plaza, en frente de la Carnicería, quedaba reservada para mercaderes de frutas y verduras, con una «calle» dando a la puerta de la Carnicería ${ }^{17}$.

En los límites orientales y occidentales de la Plaza Mayor, había otros puestos próximos a los soportales. Por el lado occidental, donde faltan fragmentos significativos del dibujo, el dibujante indica en líneas oscuras lo que parece ser cercas con plantas o árboles. La única notación en el plano, indica que se vendían turrones en los soportales occidentales. Gran parte de la zona parece estar reservada para estacionamiento de coches ${ }^{18}$.

Finalmente, el dibujo incluye una planta detallada de la parte frontal de la Panadería (Fig. 4). La representación es la más antigua que queda de la disposición del edificio, que ha sido calificado como el más majestuoso de las obras públicas madrileñas. Comparado con un detalle del bastante conocido plano de la Plaza Mayor de 1636, el plano de la Panadería nos ofrece nuevos aspectos interesantes de su arquitectura como las dos escaleras linderas (Fig. 5).

El alarife Diego Sillero, quien construyó la Panadería siguiendo los diseños de Juan de Valencia, hizo una memoria sobre el estado del edificio en junio de 1594 en el momento en que iba a comenzar la construcción en la planta baja ${ }^{19}$. Declaró Sillero que la planta baja sería costosa para construir, por las «muy gruesas maderas como de mucha cantidad de ellas». Especificando los gastos, el alarife mencionó el aspecto singular del edificio: un vestíbulo de treinta y dos columnas de piedra; cada una requeriría cuatro pares de bueyes para transportarla a la obra. Como indica el plano de 1625, el vestíbulo de la Panadería podría fácilmente haber sido partido y adaptado a las necesidades de vendedores y distribuidores de pan.

Sillero notaba más allá en su memoria de 1594, que la entrada y los arcos de la Panadería serían construidos de piedra, en vez de madera. El pórtico clásico de la Panadería, destacado del resto de la plaza, sirvió claramente para enoblecer el edificio público. Ilustraba el gusto arquitectónico que Felipe II y sus arquitectos establecieron en las obras reales, como el recientemente terminado patio de la Lonja de Sevilla. Es curioso que la Panadería no fuese un proyecto real, en el sentido más estricto de la definición. Como la Carnicería, estuvo subvencionada en parte por impuestos de comestibles, de cuyos réditos se beneficiaba principalmente la Villa. No obstante, en documentos de los años 1590, Sillero hace referencia al edificio como la «panadería real» ${ }^{20}$. La Panadería, un edificio público como la Plaza Mayor, sirvió claramente al embellecimiento de la nueva capital.

JESÚs R. ESCOBAR Fairfield University

17 Sobre la legislación del 4 de enero de 1584, véase Archivo Histórico Nacional: Consejos, libro 1197, fols. $97 \mathrm{r}-98 \mathrm{r}$.

${ }_{18}$ En varias ocasiones, durante los primeros años del siglo XVII, los alcaldes de Corte prohibieron el estacionamiento en la zona de la Puerta de Guadalajara y Panadería durante las horas del mercado (desde las nueve de la mañana hasta las dos de la tarde). Véase Archivo Histórico Nacional: Consejos, libro 1203, fols. 121 y 125 , y Archivo Histórico Nacional: Consejos, libro 1209.

19 AVM: Secretaría 3-91-25, 13 de junio de 1594.

20 Véase, por ejemplo, Archivo Histórico de Protocolos de Madrid: Protocolo 1593, fols. 18-21, 20 de octubre de 1597. 

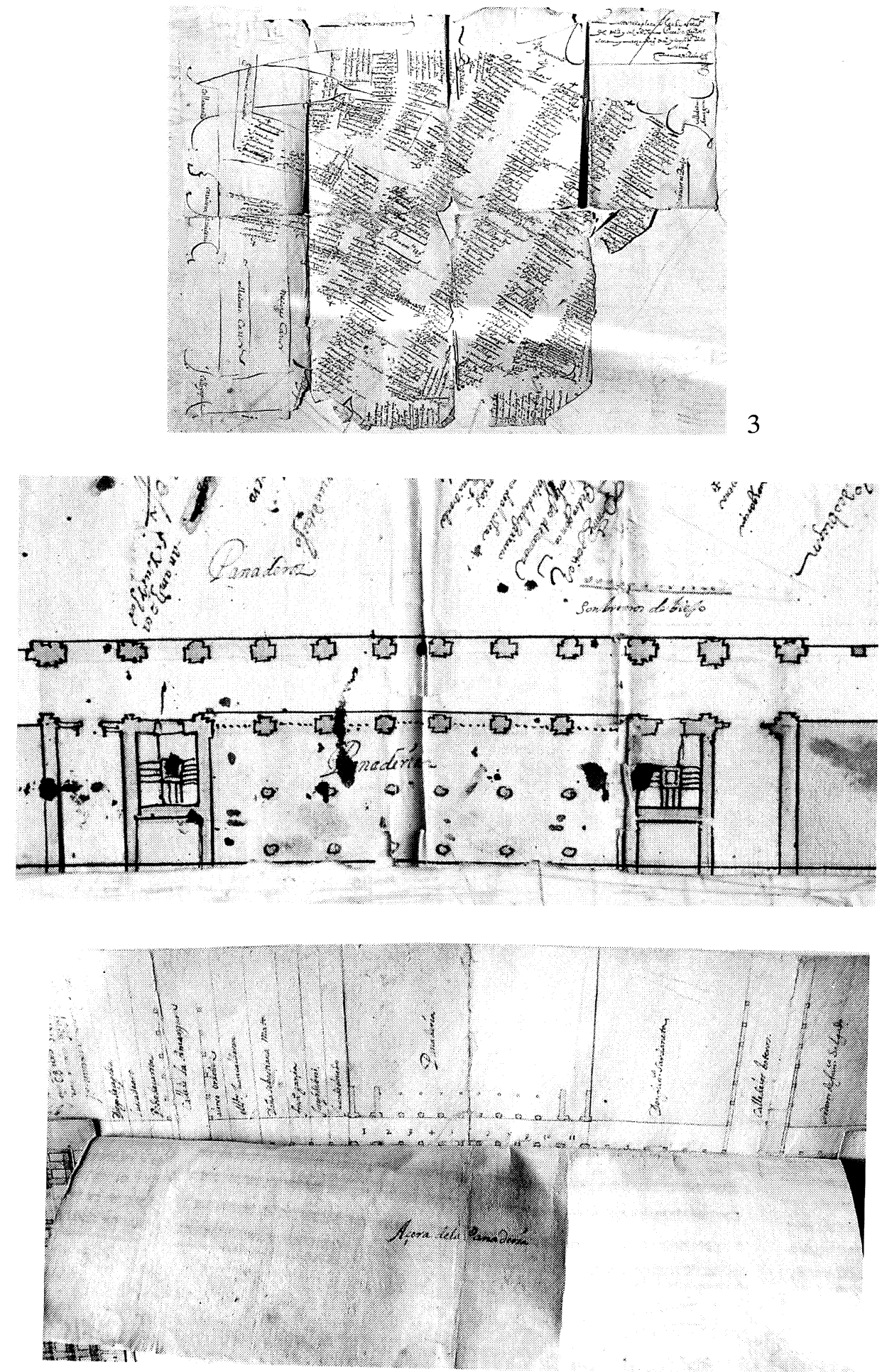

Figura 3. Manuel de Robles, Plano esquimático de la Plaza Mayor de Madrid, 1625, Madrid, Archivo de Villa. Figura 4. Taller de Juan Gómez de Mora, Plano de la Plaza Mayor de Madrid, detalle de la Panadería, c. 1625, Madrid, Archivo de Villa.

Figura 5. Juan Gómez de Mora, Plano de la Plaza Mayor de Madrid, detalle de la Panadería, 1636, Madrid, Archivo de la Villa. 